Variiert Schusteri schon bereits in der Weise, daß der eine mittlere Punkt jederseits in zwei schwache Pünktchen, die nicht mehr stark sichtbar sind, aufgelöst ist (einen solchen Typ besitze ich und diese ergänzende Definition wäre eine Erweiterung zu der von v. Heyden unter 3. gegebenen), so habe ich im vorigen Sommer (1906) noch eine Form gefunden (somit die 12.), die Schusteri am nächsten steht und die ich hiermit $\operatorname{Cr}$. asparayi a. moguntiaca Schust. benenne. Auch die beiden mittleren Flecke (ursprünglich mittlere Binde) sind bei ihr gänzlich verschwunden und es ist daselbt eine rein weiße Fläche. Nach einem Exemplar das bei Mainz gefangen wurde.

\title{
Ein neuer Microtelus (Sol.) aus Aegypten.
}

(Coleoptera, Tenebrionidae.)

Von Edm. Reitter in Paskau (Mähren).

\section{Microtelus binodiceps n. sp.}

Mit $M$. cariniceps Rche. (Reitter in Deutsch. Ent.Ztsch, 1886, 128) verwandt, aber viel größer, die Fühler etwas dicker, das dritte Glied ist dreimal so lang als breit, die verkürzten Scheitelrippen auf zwei Beulen reduziert, Flügeldecken lang oval, schmäler, die Punkte der Reihen dicht gestellt, der äußere Zwischenraum der Rippen ist vorne von oben nicht sichtbar. Long. $5-6 \cdot 2 \mathrm{~mm}$.

Körper schwarzbraun, matt.

Alle übrigen Arten haben am Scheitel, zwischen der Mittelund inneren Augenrippe weder Beulen noch Rippenrudimente.

Aegypten, Moabland.

\section{Aromia moschata v. laevicollis nov.}

Von der Stammform durch im größten Umfange spiegelglatte Scheibe des Halsschildes unterschieden. Auf derselben sind nur ganz vereinzelte Punkte eingestochen; auch der Vorder- und Hinterrand ist glatt.

Zahlreiche Exemplare wurden bei Paskau aufgefunden; auch sammelte Herr Oskar Salbach einige im Engadin. Edm. Reitter. 


\section{$2 \mathrm{BHL}$ Biodiversity Heritage Library}

Reitter, Edmund. 1907. "Ein neuer Microtelus (SOL.) aus Aegypten. (Coleoptera, Tenebrionidae)." Wiener entomologische Zeitung 26, 115. https://doi.org/10.5962/bhl.part.8880.

View This Item Online: https://www.biodiversitylibrary.org/item/45299

DOI: https://doi.org/10.5962/bhl.part.8880

Permalink: https://www.biodiversitylibrary.org/partpdf/8880

\section{Holding Institution}

Smithsonian Libraries

\section{Sponsored by}

Smithsonian

\section{Copyright \& Reuse}

Copyright Status: NOT_IN_COPYRIGHT

This document was created from content at the Biodiversity Heritage Library, the world's largest open access digital library for biodiversity literature and archives. Visit BHL at https://www.biodiversitylibrary.org. 